\title{
Objectively measured light-intensity lifestyle activity and sedentary time are independently associated with metabolic syndrome: a cross-sectional study of Japanese adults
}

Junghoon Kim ${ }^{1,2}$, Kai Tanabe , Noriko Yokoyama', Hirofumi Zempo ${ }^{1}$ and Shinya Kuno ${ }^{\text {1* }}$

\begin{abstract}
Background: Reducing sedentary time and increasing lifestyle activities, including light-intensity activity, may be an option to help prevent metabolic syndrome (MetS). The purpose of the present study was to examine whether objectively measured light-intensity lifestyle activity and sedentary time is associated with MetS, independent of moderate-vigorous intensity physical activity (MVPA).

Methods: The participants in this cross-sectional study were 483 middle-aged Japanese adults, aged 30-64 years. The participants were divided into those with or without MetS according to the Japanese criteria for MetS. A triaxial accelerometer was used to measure light-intensity lifestyle activity [1.6-2.9 metabolic equivalents (METs)] and sedentary time ( $\leq 1.5 \mathrm{METS}$ ). Logistic regression was used to predict MetS from the levels of light-intensity lifestyle activity and sedentary time with age, sex, smoking, calorie intake, accelerometer wear time, and MVPA as covariates.

Results: The odds ratios (OR) for MetS in the highest and middle tertiles of light-intensity lifestyle activity were 0.44 [95\% confidence interval (Cl): 0.24 to 0.81 ] and 0.51 ( $95 \%$ Cl: 0.29 to 0.89 ) relative to the lowest tertile, after adjustment for age, sex, smoking, calorie intake, accelerometer wear time and MVPA $\left(P_{\text {trend }}=0.012\right)$. Sedentary time was also associated with the risk of MetS $\left(P_{\text {trend }}=0.018\right)$. Among participants in the highest tertile of sedentary time, the risk of MetS was 2.27-times greater than that in the lowest tertile (95\% Cl: 1.25 to 4.11). The risk of MetS was not significantly increased in subjects in the middle tertile of sedentary time.

Conclusions: We found that light-intensity lifestyle activity and sedentary time were significantly associated with the risk of MetS, independent of MVPA. The results of our study suggest that public health messages and guidelines should be refined to include increases in light-intensity lifestyle activity and/or decreases in sedentary time, alongside promoting MVPA, to prevent MetS.
\end{abstract}

Keywords: Lifestyle activity, Light-intensity activity, Metabolic syndrome, Sedentary time

\section{Introduction}

Metabolic syndrome (MetS) is a cluster of risk factors that increase an individual's risk of developing cardiovascular disease [1]. Individuals with MetS are at greater risk of developing type 2 diabetes $[2,3]$ and atherosclerotic cardiovascular disease compared with individuals without MetS. The cardiovascular disease mortality rate is also higher among people with MetS [4,5].

\footnotetext{
* Correspondence: kuno@taiiku.tsukuba.ac.jp

'Department of Sports Medicine, Graduate School of Comprehensive Human Sciences, University of Tsukuba, Tsukuba, Ibaraki 305-8577, Japan Full list of author information is available at the end of the article
}

Epidemiological studies have consistently shown that moderate-vigorous intensity physical activity (MVPA) is associated with the risk of MetS [6-9]. Most studies of physical activity have focused on MVPA in leisure time because it involves greater energy expenditure, increases physical fitness, and decreases the risk of MetS [9-12]. In Japan, The Exercise and Physical Activity Reference for Health Promotion report 2006 (EPAR2006) compiled the then current guidelines for health promotion and provides recommendations for physical activity for Japanese individuals [13]. These guidelines, aimed at 
preventing lifestyle-related diseases, recommend that adults accumulate 23 metabolic equivalent (MET)-h/week of MVPA exceeding 3 METs [13]. However, for most people it is difficult to meet the recommended amount of physical activity from only MVPA.

In fact, only $\sim 30 \%$ of Japanese adults were reported to fulfill the recommended physical activity level [14], so other types of physical activity should be considered. It is also important to determine whether lifestyle activities, including light-intensity activities, can improve health [15-17]. Light-intensity activities, such as walking slowly around the home, store or office, and other housework or workplace activities $[18,19]$, are the main determinant of variability in total daily energy expenditure $[20,21]$.

Furthermore, it was reported that sedentary behavior is associated with MetS and its components, independent of MVPA, in studies in Western countries, including the USA and Australia [22-25]. Several studies that objectively measured sedentary time using accelerometers showed that these factors are associated with MetS risk factors in adults $[15,26,27]$. These observations suggest the need for more recommendations regarding the health benefits of increases in light-intensity lifestyle activity and decreases in sedentary time. Nevertheless, the potential influence of lifestyle activities and sedentary time on MetS is poorly understood, particularly in Japanese individuals. Thus, the purpose of the present study was to examine whether objectively measured light-intensity lifestyle activity and sedentary time is associated with MetS, independent of MVPA.

\section{Methods}

\section{Participants}

A description of the study participants, design and methods used in this study are reported in our previous study [28]. In brief, we performed a cross-sectional study of 521 healthy middle-aged Japanese adults without diabetes, cardiovascular disease or musculoskeletal diseases living in Tsukuba City who underwent medical examinations. Participants were recruited through advertisements placed in local newspapers. In this analysis, we excluded individuals with missing data on physical activity $(\mathrm{n}=11)$, missing MetS components $(\mathrm{n}=18)$ and missing dietary intake $(n=9)$. Therefore, 483 participants (179 men and 304 women) were included in this analysis [mean \pm standard deviation (SD) age, $47.9 \pm 9.0$ years; body mass index (BMI), $25.6 \pm 4.0 \mathrm{~kg} / \mathrm{m}^{2}$ ]. The characteristics of the participants included in this analysis are presented in Table 1. This study was approved by the Ethical Committee of the Institute of Health and Sport Sciences and the Institute of Clinical Medicine at the University of Tsukuba. All participants provided written informed consent.
Table 1 Participant characteristics

\begin{tabular}{ll}
\hline Demographics & Mean \pm SD or \% \\
\hline$N$ & 483 \\
Sex (men, \%) & 37.1 \\
Age (years) & $47.9 \pm 9.0$ \\
$30-39$ years (\%) & 22.2 \\
$40-49$ years (\%) & 33.5 \\
$50+$ years (\%) & 44.3 \\
BMI (kg/m ${ }^{2}$ ) & $25.6 \pm 4.0$ \\
Obese (BMI $\geq 25$ kg/m $\left.{ }^{2}, \%\right)$ & 51.3 \\
\hline Physical activity parameters & \\
Sedentary time (h/day) & $4.6 \pm 1.8$ \\
Light-intensity activity (METs-h/day) & $12.8 \pm 3.6$ \\
MVPA (METs-h/day) & $3.6 \pm 1.5$ \\
\hline Percentage of subject with & \\
MetS & 23.2 \\
Abdominal obesity & 52.3 \\
Hypertension & 50.1 \\
Hyperglycemia & 22.8 \\
Dyslipidemia & 21.5 \\
\hline Calorie intake (kcal/day) & $1983.2 \pm 310.6$ \\
Smoker (\%) & 11.6 \\
\hline BMl body mass $n$ &
\end{tabular}

$B M I$, body mass index; $M E T$, metabolic equivalent; $M V P A$, moderate-vigorous intensity physical activity; MetS, metabolic syndrome; Abdominal obesity: waist circumference $\geq 85 \mathrm{~cm}$ in men, $\geq 90 \mathrm{~cm}$ in women; hypertension: systolic blood pressure $\geq 130 \mathrm{mmHg}$ and/or diastolic blood pressure $\geq 85 \mathrm{mmHg}$; hyperglycemia: blood glucose $\geq 110 \mathrm{mg} / \mathrm{dL}$; dyslipidemia: triglyceride $\geq$ $150 \mathrm{mg} / \mathrm{dL}$ and/or high-density lipoprotein cholesterol level $<40 \mathrm{mg} / \mathrm{dL}$.

\section{Physical activity and sedentary time}

Physical activity and sedentary time were measured using a triaxial accelerometer (HJA-350IT, Active style Pro, Omron Healthcare Co., Ltd.) $[28,29]$. To ensure the data were valid and reflected regular day-to-day activities, the participants were instructed to wear the accelerometer for 7 days while continuing regular daily activities [30]. The participants were instructed to wear the accelerometer on the right hip throughout the day from the time they woke up in the morning until they went to bed at night, except during showers or bathing.

All acceleration data were recorded as mean values of 1-min epochs. Periods of time in which accelerometer data were not recorded for $\geq 1$ min were defined as the 'nonwear' time. Participants who did not record at least 600 min of activity every day for 7 days were excluded from further analyses [30]. Accelerometer data were calculated as the time spent in each of three different intensity levels for 7 days as follows: sedentary time, $\leq 1.5$ METs; lightintensity lifestyle activity, 1.6-2.9 METs, and MVPA, $\geq 3$ METs [31,32]. To examine the effects of different levels of light-intensity lifestyle activity on the risk of MetS, we divided participants into tertiles of light-intensity lifestyle activity (< 11.1, 11.2-14.5 and $\geq 14.6 \mathrm{MET}-\mathrm{h} /$ day $)$ and 
sedentary time $(<3.5,3.5-5.3$ and $\geq 5.4 \mathrm{~h} /$ day $)$. We confirmed the validity and reliability of the accelerometer in our previous study. The percentage of time that the accelerometer correctly discriminated sedentary (PC work), moderate (normal and brisk walking) and vigorous intensity (jogging) activity was $>95.5 \%$, while the percentage for light-intensity activity (slow walking) was $81.8 \%$ [29].

\section{Anthropometric measurements}

Body weight was measured to the nearest $0.1 \mathrm{~kg}$ using a digital scale without shoes. Height was measured to the nearest $0.1 \mathrm{~cm}$ using a wall-mounted stadiometer. BMI was calculated from body weight and height $\left(\mathrm{kg} / \mathrm{m}^{2}\right)$. Waist circumference (WC) was measured three times to the nearest $0.1 \mathrm{~cm}$ using a calibrated measuring tape at the midpoint of the lower costal margin; the mean value was used in the analyses.

\section{Metabolic syndrome components}

Blood pressure was measured using an automated sphygmomanometer (SM-100; OMRON, Kyoto, Japan) with the participant in the seated position after resting for $\geq 10 \mathrm{~min}$. A blood sample $(\sim 10 \mathrm{~mL})$ was drawn from all participants after $\mathrm{a} \geq 12$-h fast.

The Japanese criteria for MetS were used to evaluate the prevalence of MetS [33,34], and consisted of abdominal obesity (WC $\geq 85 \mathrm{~cm}$ in men and $\geq 90 \mathrm{~cm}$ in women) as an essential criterion plus any two of the following three factors: (1) dyslipidemia [triglyceride (TG) $\geq$ $150 \mathrm{mg} / \mathrm{dL}$ and/or high density lipoprotein cholesterol (HDL-C) level $<40 \mathrm{mg} / \mathrm{dL}$ or specific treatment for these lipid abnormalities]; (2) blood pressure $\geq 130 / 85 \mathrm{mmHg}$ or on drug treatment; and (3) fasting glucose $\geq 110 \mathrm{mg} /$ dL. MetS components were also standardized by calculating $\mathrm{Z}$ scores for each participant $[\mathrm{Z}=$ (value - mean)/ $\mathrm{SD}$. We constructed a continuous clustered MetS score from the sum of each $\mathrm{Z}$ score, similar to that done in a previous study [16], as follows: zWC + zBoold pressure [(systolic blood pressure + diastolic blood pressure $) / 2]+$ zFasting glucose + zTG + and inverted zHDL-C.

\section{Covariates}

Energy intake was assessed using 3-day weighed dietary records. The food data of the dietary records were converted to energy and nutrient data by a dietician and were analyzed using Eiyoukun software version 4.0 (Kenpakusya, Tokyo, Japan). The participants also answered questions about smoking status, and the use antihypertensive and antidyslipidemic drugs using a general health questionnaire. Smoking status was classified as never or current smoking.

\section{Statistical analysis}

Values are expressed as means \pm standard deviation of the mean or percentage. Values of $P<0.05$ were considered statistically significant. All data were analyzed using $\mathrm{R}$ version 2.14.0 [35]. Although we evaluated interactions by sex between light-intensity lifestyle activity or sedentary time, and the components of MetS, the interactions were not significant. Therefore, in analyses of physical activity and sedentary time, men and women were evaluated as a single group, as described in Additional file 1: Table S1 and Additional file 2: Table S2.

The statistical significance for linearity between lightintensity lifestyle activity and sedentary time categories was evaluated using Cochran-Armitage trend tests. Generalized linear models were used to predict the continuous components of MetS and clustered metabolic score based on light-intensity lifestyle activity and sedentary time. These models included age, sex, smoking, calorie intake and MVPA as covariates. Light-intensity activity and sedentary time were included in the analyses in 1-h units.

Logistic regression was also used to predict the prevalence of MetS and its components from the levels of light-intensity lifestyle activity and sedentary time. All logistic regression models included the following covariates: age, sex, smoking, calorie intake, accelerometer wear time and MVPA. We determined the variance inflation factors (VIF) for multicollinearity in all generalized linear models and logistic regression models as previously described [36], but these were not significant as all VIF values were $<10$.

\section{Results}

The characteristics of the participants are presented in Table 1 . The present analysis included 483 Japanese population aged $30-64$ years. Overall, $23.2 \%$ of the participants had MetS (Table 1). The mean sedentary time was $4.6 \mathrm{~h} /$ day. Light-intensity lifestyle activity and MVPA were 12.8 and 3.6 METs-h/day, respectively.

Table 2 shows the frequency of MetS and its components according to levels of light-intensity lifestyle activity. As shown in the table, the levels of light-intensity lifestyle activity were significantly and negatively associated with the frequencies of MetS $\left(P_{\text {trend }}=0.001\right)$, abdominal obesity $\left(P_{\text {trend }}<0.001\right)$ and dyslipidemia $\left(P_{\text {trend }}<0.001\right)$. By contrast, the frequencies of hypertension and hyperglycemia were not significantly different among levels of lightintensity lifestyle activity (Table 2). Table 2 also shows that sedentary time was significantly and positively associated with the frequencies of MetS $\left(P_{\text {trend }}=0.002\right)$, abdominal obesity $\left(P_{\text {trend }}=0.004\right)$ and dyslipidemia $\left(P_{\text {trend }}<0.001\right)$. On the other hand, the frequencies of hypertension and hyperglycemia were not significantly different among tertiles sedentary time (Table 2).

Table 3 shows the results of the generalized linear models of light-intensity lifestyle activity and sedentary time. Light-intensity lifestyle activity was significantly associated with WC $(\beta=-0.827 ; 95 \%$ CI: -1.518 
Table 2 Frequency (\%) of MetS and its components according to tertiles of light-intensity lifestyle activity and sedentary time in daily life

\begin{tabular}{|c|c|c|c|c|}
\hline & \multicolumn{3}{|c|}{$\begin{array}{l}\text { Light-intensity lifestyle activity } \\
\text { (METs-h/day) }\end{array}$} & \multirow[b]{2}{*}{$\begin{array}{c}P \text {-value } \\
\text { for } \\
\text { trend }\end{array}$} \\
\hline & $\begin{array}{c}<11.1 \\
\text { METs-h/day } \\
(n=161)\end{array}$ & $\begin{array}{c}11.2-14.5 \\
\text { METs-h/day } \\
(n=161)\end{array}$ & $\begin{array}{c}\geq 14.6 \\
\text { METs-h/day } \\
(n=161)\end{array}$ & \\
\hline MetS (\%) & 34.8 & 19.3 & 15.5 & 0.001 \\
\hline Abdominal obesity (\%) & 67.7 & 46.3 & 43.1 & $<0.001$ \\
\hline Hypertension (\%) & 51.6 & 50.3 & 48.3 & 0.641 \\
\hline Hyperglycemia (\%) & 26.9 & 19.3 & 22.4 & 0.449 \\
\hline \multirow[t]{3}{*}{ Dyslipidemia (\%) } & 33.5 & 20.5 & 10.6 & $<0.001$ \\
\hline & \multicolumn{3}{|c|}{ Sedentary time (h/day) } & \\
\hline & $\begin{array}{c}<3.5 \\
\text { h/day } \\
(n=161)\end{array}$ & $\begin{array}{c}3.5-5.3 \\
\text { h/day } \\
(n=161)\end{array}$ & $\begin{array}{c}\geq 5.4 \\
\text { h/day } \\
(n=161)\end{array}$ & $\begin{array}{c}P \text {-value } \\
\text { for } \\
\text { trend }\end{array}$ \\
\hline MetS (\%) & 15.5 & 20.3 & 34.4 & 0.002 \\
\hline Abdominal obesity (\%) & 41.6 & 54.1 & 61.9 & 0.004 \\
\hline Hypertension (\%) & 48.2 & 53.8 & 48.4 & 0.977 \\
\hline Hyperglycemia (\%) & 22.6 & 20.3 & 25.6 & 0.613 \\
\hline Dyslipidemia (\%) & 10.7 & 19.0 & 35.7 & $<0.001$ \\
\hline
\end{tabular}

Values are percentages. $P$-value for trend were calculated using the CochranArmitage Test. MetS, metabolic syndrome; $M E T$, metabolic equivalent.

Abdominal obesity: waist circumference $\geq 85 \mathrm{~cm}$ in men, $\geq 90 \mathrm{~cm}$ in women; hypertension: systolic blood pressure $\geq 130 \mathrm{mmHg}$ and/or diastolic blood pressure $\geq 85 \mathrm{mmHg}$; hyperglycemia: blood glucose $\geq 110 \mathrm{mg} / \mathrm{dL}$; dyslipidemia: triglyceride $\geq 150 \mathrm{mg} / \mathrm{dL}$ and/or high-density lipoprotein cholesterol level $<40 \mathrm{mg} / \mathrm{dL}$.

to -0.137 ), HDL-C ( $\beta=1.118$; 95\% CI: 0.188 to 2.049 ) and clustered MetS risk score $(\beta=-0.249 ; 95 \%$ CI: -0.448 to -0.051$)$, after adjusting for age, sex, smoking, calorie intake, accelerometer wear time and MVPA, but not with SBP, DBP, fasting glucose or TG. Sedentary time was significantly associated with WC $(\beta=1.034$; 95\% CI: 0.462 to 1.606$)$, fasting glucose $(\beta=1.020 ; 95 \%$ CI: 0.015 to 2.025$)$, TG $(\beta=5.815 ; 95 \% \mathrm{CI}: 1.791$ to 9.838), HDL-C ( $\beta=-1.491 ; 95 \%$ CI: -2.262 to -0.720$)$ and zMetS ( $\beta=0.329 ; 95 \%$ CI: 0.164 to 0.494 ), but not with SBP or DBP.
The results of logistic regression analyses comparing the prevalence of MetS across tertiles of light-intensity lifestyle activity and sedentary time are shown in Tables 4 and 5, respectively. The odds ratios (OR) for MetS in the highest and middle tertiles of light-intensity lifestyle activity were 0.44 (95\% CI: 0.24 to 0.81 ) and 0.51 (95\% CI: 0.29 to 1.89 ) relative to the lowest tertile (Table $3, P$ trend $=0.012$ ). The levels of light-intensity lifestyle activity were also significantly associated with a reduced risk for abdominal obesity $\left(P_{\text {trend }}=0.005\right)$ and dyslipidemia $\left(P_{\text {trend }}=0.016\right)$.

We also found higher risks for MetS, abdominal obesity and dyslipidemia in subjects in the highest tertile of sedentary time after adjusting for age, smoking, calorie intake, accelerometer wear time and MVPA. This association was significant for subjects in the highest tertile of sedentary time compared with the lowest tertile, but not in the middle tertile (Table 5).

\section{Discussion}

In the present study, we determined the effects of objectively measured light-intensity lifestyle activity and sedentary time on the prevalence of MetS in Japanese adults. The major finding of our study is that both lightintensity lifestyle activity and sedentary time are significantly associated with MetS, independent of MVPA. Most of the earlier studies investigating the relationship between physical activity and MetS focused on selfreported MVPA in leisure time [6-9]. To prevent lifestyle-related diseases, the EPAR2006 recommends that adults engage in $23 \mathrm{METs}-\mathrm{h} /$ week of MVPA [13]. However, for most people it is difficult to achieve this level of MVPA in leisure time. In 2009, Shibata et al. reported that only $\sim 30 \%$ of Japanese adults engaged in the recommended level of MVPA [14]. On the other hand, several recent studies have revealed that lifestyle activity in daily life is associated with health benefits in adults [15-17]. For example, Camhi et al. [17] reported that the accumulation of light-intensity lifestyle activity measured using an accelerometer is independently

Table 3 Multivariable associations between light-intensity lifestyle activity or sedentary time and MetS components

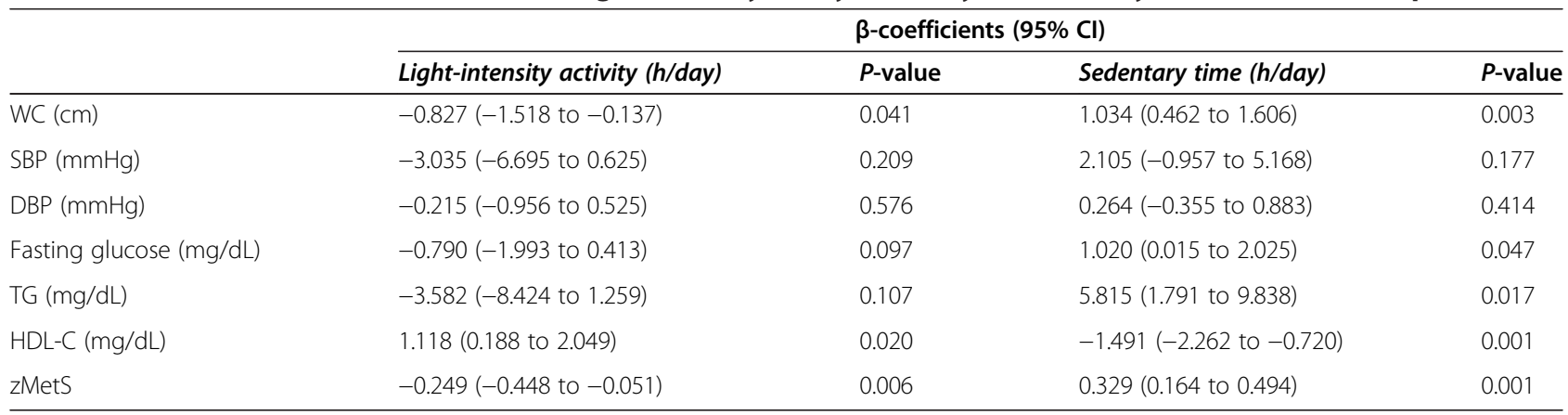

Adjusted for age, sex, smoking status, calorie intake, accelerometer wear time and moderate-vigorous intensity physical activity. MetS, metabolic syndrome; WC, waist circumference; $S B P$, systolic blood pressure; $D B P$, diastolic blood pressure; $T G$, triglyceride; $H D L-C$, high-density lipoprotein cholesterol. 
Table 4 Associations between light-intensity activity and the prevalence of MetS and its components

\begin{tabular}{|c|c|c|c|c|}
\hline \multirow[b]{2}{*}{ Outcomes } & \multicolumn{3}{|c|}{ Light-intensity activity category } & \multirow[b]{2}{*}{$P$-value for trenc } \\
\hline & $<11.1$ METs-h/day $(n=161)$ & 11.2-14.5 METs-h/day $(n=161)$ & $\geq 14.6$ METs-h/day $(n=161)$ & \\
\hline MetS & 1 (Reference) & $0.51(0.29 \text { to } 0.89)^{*}$ & $0.44(0.24 \text { to } 0.81)^{*}$ & 0.012 \\
\hline Abdominal obesity & 1 (Reference) & $0.46(0.28 \text { to } 0.76)^{*}$ & $0.50(0.30 \text { to } 0.84)^{*}$ & 0.005 \\
\hline Hypertension & 1 (Reference) & 0.98 (0.61 to 1.58$)$ & 0.97 (0.59 to 1.60$)$ & 0.993 \\
\hline Hyperglycemia & 1 (Reference) & 0.68 (0.38 to 1.23$)$ & 0.94 (0.51 to 1.72$)$ & 0.394 \\
\hline Dyslipidemia & 1 (Reference) & 0.68 (0.39 to 1.17 ) & $0.39(0.20 \text { to } 0.74)^{*}$ & 0.016 \\
\hline
\end{tabular}

${ }^{*} P<0.05$; adjusted for age, sex, smoking status, calorie intake, accelerometer wear time and moderate-vigorous intensity physical activity. OR, odds ratio; $C l$, confidence interval; MetS, metabolic syndrome; MET, metabolic equivalent. Abdominal obesity: waist circumference $\geq 85 \mathrm{~cm}$ in men and $\geq 90 \mathrm{~cm}$ in women; hypertension: systolic blood pressure $\geq 130 \mathrm{mmHg}$ and/or diastolic blood pressure $\geq 85 \mathrm{mmHg}$; hyperglycemia: blood glucose $\geq 110 \mathrm{mg} / \mathrm{dL} ; \mathrm{dyslipidemia:}$ triglyceride $\geq 150 \mathrm{mg} / \mathrm{dL}$ and/or high-density lipoprotein cholesterol level $<40 \mathrm{mg} / \mathrm{dL}$.

associated with lower odds for certain cardiometabolic risk factors. Therefore, the results of this study and previous studies suggest that public health messages and guidelines should be updated to promote light-intensity lifestyle activity and decrease sedentary time, alongside increasing MVPA.

Our results are consistent with those of another study in which higher light-intensity activity was associated with decreased 2-h plasma glucose in Australian adults without diagnosed diabetes [15]. Another study has noted that light-intensity lifestyle activity measured using an accelerometer is associated with cardiometabolic risk factors [16]. The results of the present and other studies suggest that accumulating light-intensity lifestyle activity could be a convenient approach to increase physical activity for the prevention of MetS. For example, increasing lifestyle activities, including light-intensity activities (e.g., slowly walking around the home, store or office) $[18,19]$, may be an option to increase overall physical activity to help prevent the MetS. Although lifestyle activities may not be vigorous in terms of aerobic effort, they do account for a considerable proportion of the total daily activity, and represent important sources of energy expenditure [20,21]. These activities may also contribute to the amount of daily activity required to improve health. Although MVPA is an important component of the public health message for preventing MetS, interventions aimed at replacing sedentary behavior with light-intensity activities may be more successful, particularly since $\sim 70 \%$ of Japanese people do not conduct adequate amounts of physical activity to realize any health benefits [14]. However, it is important to consider that a greater amount of lightintensity lifestyle activity may be required to prevent MetS, as compared with MVPA [12].

In this study, we also determined the impact of sedentary time on the prevalence of MetS. The prevalence of MetS was approximately 2.27-times higher among in the highest tertile of sedentary time versus the lowest tertile. These results are consistent with those of earlier studies that examined the associations among sedentary time, obesity, MetS and mortality [22-25,37]. Several factors could explain this association between sedentary time and MetS. First, sedentary time may independently predict adverse health conditions. Ford et al. [22] and Bertrais et al. [25] also reported significant associations of television viewing time and duration of computer use with MetS, independent of MVPA. Furthermore, several studies have shown that objectively measured sedentary time is associated with MetS risk factors [26,27]. Thus, dual approaches may be necessary to increase someone's physical activity or reduce sedentary time. Second, the impact of sedentary time on the risk of MetS may be the reverse of that of light-intensity activity. However, a common trait of these studies, as described above, did

Table 5 Associations between sedentary time and the prevalence of MetS and its components

\begin{tabular}{|c|c|c|c|c|}
\hline \multirow[b]{2}{*}{ Outcomes } & \multicolumn{3}{|c|}{ Sedentary time category } & \multirow[b]{2}{*}{$\begin{array}{r}P \text {-value } \\
\text { for trend }\end{array}$} \\
\hline & $\begin{array}{c}<3.5 \text { h/day } \\
(n=161)\end{array}$ & $\begin{array}{c}3.5-5.3 \text { h/day } \\
(n=161)\end{array}$ & $\begin{array}{c}\geq 5.4 \text { h/day } \\
\quad(n=161)\end{array}$ & \\
\hline MetS & 1 (Reference) & 1.30 (0.71 to 2.38 ) & $2.27(1.25 \text { to } 4.11)^{*}$ & 0.018 \\
\hline Abdominal obesity & 1 (Reference) & 1.47 (0.92 to 2.36$)$ & $1.72(1.03 \text { to } 2.86)^{*}$ & 0.091 \\
\hline Hypertension & 1 (Reference) & 1.20 (0.76 to 1.91$)$ & 0.93 (0.57 to 1.53$)$ & 0.540 \\
\hline Hyperglycemia & 1 (Reference) & 0.82 (0.46 to 1.46$)$ & 1.10 (0.61 to 1.99$)$ & 0.607 \\
\hline Dyslipidemia & 1 (Reference) & 1.68 (0.88 to 3.24$)$ & $3.00(1.60 \text { to } 5.64)^{*}$ & 0.002 \\
\hline
\end{tabular}

${ }^{*} P<0.05$; adjusted for age, sex, smoking status, calorie intake, accelerometer wear time and moderate-vigorous intensity physical activity. OR, odds ratio; $C l$, confidence interval; MetS, metabolic syndrome; MET, metabolic equivalent. Abdominal obesity: waist circumference $\geq 85 \mathrm{~cm}$ in men, $\geq 90 \mathrm{~cm}$ in women; hypertension: systolic blood pressure $\geq 130 \mathrm{mmHg}$ and/or diastolic blood pressure $\geq 85 \mathrm{mmHg}$; hyperglycemia: blood glucose $\geq 110 \mathrm{mg} / \mathrm{dL}$; dyslipidemia: triglyceride $\geq 150 \mathrm{mg} / \mathrm{dL}$ and/or high-density lipoprotein cholesterol level $<40 \mathrm{mg} / \mathrm{dL}$. 
not estimate light-intensity activity, which may confound the association between sedentary time and health outcome. Consistent with previous studies, we found only weak significant association between sedentary time and MVPA $\left(R^{2}=0.244\right)$, but sedentary time was more strongly associated with light-intensity lifestyle activity $\left(R^{2}=0.78\right)$. The proportion of participants in the highest tertile of lifestyle activity increased from $2.5 \%$ to $15.2 \%$, and $79.2 \%$ showed a change in category from the highest to middle or lowest tertiles of sedentary time $(P<0.05$, data not shown). Moreover, when we statistically controlled for differences in objectively measured lightintensity lifestyle activity, the association between sedentary time and MetS lost its significance in the logistic regression model $(P>0.1$, data not shown). Accordingly, the results of our study suggest that the effects of sedentary time on the risk of MetS are at least partly due to differences in light-intensity lifestyle activity.

\section{Strengths and limitations}

The important strength of our study is that physical activity and sedentary time were objectively measured using triaxial accelerometers. However, accelerometers are not sensitive to all activities such as biking, standing and upper-body movement. The Sedentary Behaviour Research Network (SBRN) defines sedentary behavior as any waking behavior characterized by an energy expenditure of $\leq 1.5$ METs while in a sitting or reclining posture [32]. However, in this study, we defined as sedentary time and light-intensity activity based on intensity levels (METs) as mean values of 1-min epochs. Therefore, it is possible we misclassified some instances of lightintensity activity, sedentary time and non-wear time.

A major limitation of this study is that we cannot infer causality or specify the direction of the effect because of its cross-sectional design. The prevalence of MetS in our subjects (men: 34.6\%; women: 16.4\%) was higher than that in a general population of Japanese individuals aged 30-69 years (men: 26.3\%; women: 8.3\%) included in the National Health and Nutrition Examination Survey (2009) [38]. Furthermore, the proportion of individuals who achieved the recommended MVPA level was higher in our study (52.2\%) than in the general Japanese population (30.1\%) [38]. Therefore, our current findings may not be generalizable to the Japanese population. In this study, the mean sedentary time was approximately $2-$ $3 \mathrm{~h} /$ day lower in our participants than that reported in study performed in the USA and Australia [22,27,39]. This may also represent a limitation of our study, although this may also be due to differences in accelerometer wear time, cut-off values for sedentary activity, and the methods used to enrol the participants.

Although we controlled for several covariates, there may be residual confounding by other variables, such as sociocultural factors, family history of metabolic diseases, alcohol intake and physical fitness, which may partly explain our findings. Nevertheless, we took into account factors directly associated with the prevalence of MetS including MVPA, calorie intake and smoking $[40,41]$. Despite these limitations, our findings are important from a public health perspective, particularly in terms of designing interventions aimed at promoting physical activity by focusing on lifestyle activity among middle-aged Japanese individuals.

\section{Conclusion}

In conclusion, we found that light-intensity lifestyle activity and sedentary time were associated with the risk of MetS, independent of levels of MVPA. Public health messages and guidelines should be refined to include increases in light-intensity lifestyle activity and/or decreases in sedentary time, in addition to promoting MVPA. The effectiveness of promoting light-intensity lifestyle activity on the prevention and treatment of MetS needs to be confirmed in longitudinal and intervention studies.

\section{Additional files}

Additional file 1: Table S1. Interactions by sex between light-intensity lifestyle activity and the components of MetS.

Additional file 2: Table S2. Interactions by sex between sedentary time and the components of MetS.

\section{Abbreviations}

BMI: Body mass index; Cl: Confidence interval; DBP: Diastolic blood pressure; EPAR2006: Exercise and Physical Activity Reference for Health Promotion report 2006; HDL-C: High-density lipoprotein cholesterol; MetS: Metabolic syndrome; MET: Metabolic equivalent; MVPA: Moderate-vigorous intensity physical activity; OR: Odds ratio; SBP: Systolic blood pressure; TG: Triglyceride; VIF: Variance inflation factor; WC: Waist circumference.

\section{Competing interests}

The authors declare that they have no competing interests.

\section{Authors' contributions}

JK designed the study, developed the research plans and instruments, conducted focus groups and helped write the manuscript. KT and NY transformed the accelerometer data and provided advice on statistical analyses. $\mathrm{HZ}$ helped to measure physical activity. SK was jointly responsible for the concept and design of the study. All authors read and approved the final version of the manuscript for publication.

\section{Acknowledgements}

This work was supported in part by the Japan Society for the Promotion of Science (No.231254), a Grant-in-Aid for Scientific Research (B, No.19300229), and in part by the Kai TANABE project from the Health and Labour Sciences Research Grants from the Ministry of Health, Labour and Welfare, Japan. We wish to thank the participants and clinical teams for their collaboration and work in helping with recruitment.

\section{Author details}

'Department of Sports Medicine, Graduate School of Comprehensive Human Sciences, University of Tsukuba, Tsukuba, Ibaraki 305-8577, Japan. ²Japan Society for the Promotion of Science, Tokyo, Japan. 
Received: 15 March 2012 Accepted: 26 February 2013

Published: 4 March 2013

\section{References}

1. Reaven GM: Role of insulin resistance in human disease. Diabetes 1988, 37:1595-1607

2. Laaksonen DE, Lakka HM, Niskanen LK, Kaplan GA, Salonen JT, Lakka TA: Metabolic syndrome and development of diabetes mellitus: application and validation of recently suggested definitions of the metabolic syndrome in a prospective cohort study. Am J Epidemiol 2002, 156:1070-1077.

3. Lorenzo C, Okoloise M, Williams K, Stern MP: The metabolic syndrome as predictor of type 2 diabetes: the San Antonio heart study. Diabetes Care 2003, 26:3153-3159.

4. Lakka HM, Laaksonen DE, Lakka TA, Niskanen LK, Kumpusalo E, Tuomilehto J, Salonen JT: The metabolic syndrome and total and cardiovascular disease mortality in middle-aged men. JAMA 2002, 288:2709-2716.

5. Hu G, Qiao Q, Tuomilehto J, Balkau B, Borch-Johnsen K, Pyorala K: Prevalence of the metabolic syndrome and its relation to all-cause and cardiovascular mortality in nondiabetic European men and women. Arch Intern Med 2004, 164:1066-1076.

6. Brien SE, Katzmarzyk PT: Physical activity and the metabolic syndrome in Canada. Appl Physiol Nutr Metab 2006, 31:40-47.

7. Lakka TA, Laaksonen DE: Physical activity in prevention and treatment of the metabolic syndrome. App/ Physio/ Nutr Metab 2007, 32:76-88.

8. Yang X, Telama R, Hirvensalo M, Mattsson N, Viikari JS, Raitakari OT: The longitudinal effects of physical activity history on metabolic syndrome. Med Sci Sports Exerc 2008, 40:1424-1431.

9. Rennie KL, McCarthy N, Yazdgerdi S, Marmot M, Brunner E: Association of the metabolic syndrome with both vigorous and moderate physical activity. Int J Epidemiol 2003, 32:600-606.

10. Lee IM, Paffenbarger RS Jr: Associations of light, moderate, and vigorous intensity physical activity with longevity. The Harvard Alumni Health Study. Am J Epidemiol 2000, 151:293-299.

11. Jeon CY, Lokken RP, Hu FB, van Dam RM: Physical activity of moderate intensity and risk of type 2 diabetes: a systematic review. Diabetes Care 2007, 30:744-752.

12. Janssen I, Ross R: Vigorous intensity physical activity is related to the metabolic syndrome independent of the physical activity dose. Int J Epidemiol 2012, 41:1132-1140.

13. General Affairs Division, Health Service Bureau, Ministry of Health, Labour and Welfare of Japan: Exercise and physical activity reference quantity for health promotion 2006 (EPAR2006)-Physical activity, Exercise, and Physical Fitness. [http://www.nih.go.jp/eiken/programs/pdf/epar2006.pdf]

14. Shibata A, Oka K, Harada K, Nakamura Y, Muraoka I: Psychological, social, and environmental factors to meeting physical activity recommendations among Japanese adults. Int J Behav Nutr Phys Act 2009, 6:60.

15. Healy GN, Dunstan DW, Salmon J, Cerin E, Shaw JE, Zimmet PZ, Owen N: Objectively measured light-intensity physical activity is independently associated with 2-h plasma glucose. Diabetes Care 2007, 30:1384-1389.

16. Healy GN, Wijndaele K, Dunstan DW, Shaw JE, Salmon J, Zimmet PZ, Owen $\mathrm{N}$ : Objectively measured sedentary time, physical activity, and metabolic risk: the Australian Diabetes, Obesity and Lifestyle Study (AusDiab). Diabetes Care 2008, 31:369-371.

17. Camhi SM, Sisson SB, Johnson WD, Katzmarzyk PT, Tudor-Locke C. Accelerometer-determined moderate intensity lifestyle activity and cardiometabolic health. Prev Med 2011, 52:358-360.

18. Ainsworth BE, Haskell WL, Whitt MC, Irwin ML, Swartz AM, Strath SJ, O'Brien WL, Bassett DR, Schmitz KH, Emplaincourt PO, Jacobs DR, Leon AS: Compendium of physical activities: an update of activity codes and MET intensities. Med Sci Sports Exerc 2000, 32:S498-S504.

19. Haskell WL, Lee IM, Pate RR, Powell KE, Blair SN, Franklin BA, Macera CA, Heath GW, Thompson PD, Bauman A: Physical activity and public health: updated recommendation for adults from the American College of Sports Medicine and the American Heart Association. Med Sci Sports Exerc 2007, 39:1423-1434.

20. Donahoo WT, Levine JA, Melanson EL: Variability in energy expenditure and its components. Curr Opin Clin Nutr Metab Care 2004, 7:599-605.

21. Hamilton MT, Hamilton DG, Zderic TW: Role of low energy expenditure and sitting in obesity, metabolic syndrome, type 2 diabetes, and cardiovascular disease. Diabetes 2007, 56:2655-2667.
22. Ford ES, Kohl HW, Mokdad AH, Ajani UA: Sedentary behavior, physical activity, and the metabolic syndrome among U.S. adults. Obes Res 2005, 13:608-614

23. Bertrais S, Beyeme-Ondoua JP, Czernichow S, Galan P, Hercberg S, Oppert JM: Sedentary behaviors, physical activity, and metabolic syndrome in middle-aged French subjects. Obes Res 2005, 13:936-944.

24. Mabry RM, Winkler EA, Reeves MM, Eakin EG, Owen N: Associations of Physical Activity and Sitting Time With the Metabolic Syndrome Among Omani Adults. Obesity (Silver Spring) 2012:. doi:10.1038/oby.2012.26.

25. Stamatakis E, Hamer M, Tilling K, Lawlor DA: Sedentary time in relation to cardio-metabolic risk factors: differential associations for self-report vs accelerometry in working age adults. Int J Epidemio/ 2012, 41:1328-1337.

26. Bankoski A, Harris TB, McClain JJ, Brychta RJ, Caserotti P, Chen KY, Berrigan D, Troiano RP, Koster A: Sedentary activity associated with metabolic syndrome independent of physical activity. Diabetes Care 2011, 34:497-503.

27. Healy GN, Dunstan DW, Salmon J, Cerin E, Shaw JE, Zimmet PZ, Owen N: Breaks in sedentary time: beneficial associations with metabolic risk. Diabetes Care 2008, 31:661-666.

28. Kim J, Tanabe K, Yokoyama N, Zempo H, Kuno S: Association between physical activity and metabolic syndrome in middle-aged Japanese: a cross-sectional study. BMC Public Health 2011, 11:624.

29. Oshima Y, Kawaguchi K, Tanaka S, Ohkawara K, Hikihara Y, Ishikawa-Takata K, Tabata I: Classifying household and locomotive activities using a triaxial accelerometer. Gait Posture 2010, 31:370-374.

30. Trost SG, Pate RR, Freedson PS, Sallis JF, Taylor WC: Using objective physical activity measures with youth: how many days of monitoring are needed? Med Sci Sports Exerc 2000, 32:426-431.

31. Pate RR, O'Neill JR, Lobelo F: The evolving definition of "sedentary". Exerc Sport Sci Rev 2008, 36:173-178.

32. Sedentary Behaviour Research Network: Letter to the editor: standardized use of the terms "sedentary" and "sedentary behaviours". Appl Physiol Nutr Metab 2012, 37:540-542.

33. The Examination Committee of Criteria for 'Metabolic Syndrome' in Japan: Criteria for 'metabolic syndrome' in Japan. J Jpn Soc Int Med 2005, 94:188-203 [in Japanese].

34. Fujita T: The metabolic syndrome in Japan. Nat Clin Pract Cardiovasc 2008, 5:15-18.

35. R Development Core Team: R: A Language and Environment for Statistical Computing. Vienna, Austria: R Foundation for Statistical Computing; 2009 [http://www.R-project.org.]. ISBN 3-900051-07-0.

36. O'Brien RM: A caution regarding rules of thumb for variance inflation factors. Quality \& Quantity 2007, 41:673-690.

37. Patel AV, Bernstein L, Deka A, Feigelson HS, Campbell PT, Gapstur SM, Colditz GA, Thun MJ: Leisure time spent sitting in relation to total mortality in a prospective cohort of US adults. Am J Epidemiol 2010, 172:419-429.

38. Ministry of Health, Labour and Welfare: National Health and Nutrition Examination Survey in 2009. 2011: [in Japanese]. [http://www.mhlw.go. jp/bunya/kenkou/eiyou/dl/h21-houkoku-01.pdf]

39. Matthews CE, Chen KY, Freedson PS, Buchowski MS, Beech BM, Pate RR, Troiano RP: Amount of time spent in sedentary behaviors in the United States, 2003-2004. Am J Epidemiol 2008, 167:875-881.

40. Riccardi G, Giacco R, Rivellese AA: Dietary fat, insulin sensitivity and the metabolic syndrome. Clin Nutr 2004, 23:447-456.

41. Ishizaka N, Ishizaka Y, Toda E, Nagai R, Yamakado M: Association between cigarette smoking, white blood cell count, and metabolic syndrome as defined by the Japanese criteria. Intern Med 2007, 46:1167-1170.

doi:10.1186/1479-5868-10-30

Cite this article as: Kim et al:: Objectively measured light-intensity lifestyle activity and sedentary time are independently associated with metabolic syndrome: a cross-sectional study of Japanese adults. International Journal of Behavioral Nutrition and Physical Activity 2013 10:30. 